those dying in hospital with obstructed airways had less severe non-respiratory injuries than those dying with clear airways. The same tendency could be discerned when the lowest $10 \%$ were considered, although the numbers of patients were very small. These results suggest strongly that airway obstruction contributes to the death of some patients in the first 72 hours of hospital care. They do not indict airway management in those who die before they reach hospital.

\section{Discussion}

This study is presented as much for its method as for its results. The introduction of the ISS will do much to help to measure performance that has hitherto been the subject of speculation. Improvement in the data retrieval systems available to accident units is, however, essential if full use is to be made of auditing techniques. Because no retrieval system was available this work was based on cumulative mortality rather than the much more satisfactory concept of mortality ratio. It follows that no observations could be made on the undoubtedly important role of airway management in the survivors.

The policy adopted for the prehospital care of accident victims remained constant throughout the five years under review (1971-5). Ambulance crews were trained in basic resuscitation techniques and called out hospital staff only to care for trapped patients. The results would suggest that this quality of care is optimum with regard to airway management and that no improvement in survival could be expected if more advanced training were introduced. In contrast, airway management during the first 72 hours in hospital does not appear to be satisfactory.
These conclusions support the views of Hoffman, ${ }^{6}$ who suggested that more deaths could be prevented in hospital than at the roadside. More recently Rose et $a l^{7}$ have shown that a significant number of patients with head injury are dying unnecessarily in hospital. The work reported here has been concerned with only one aspect of the initial care of patients injured in an urban area. Outside the large conurbations more emphasis on prehospital treatment may be required because of the long distances involved. Such treatment will include the management of hypovolaemic shock and chest injuries, which were outside the scope of this review. All these aspects of initial care could and should be subjected to audit as methods for this are now available.

I thank Dr H B Stoner, Dr D F Heath, and Professor M H Irving for advice and Mr D Blakey, HM Coroner for Greater Manchester County (West), for permission to examine the necropsy reports.

\section{References}

${ }^{1}$ Boughey, W N F, British Medical fournal, 1968, 1, 369.

2 Stoner, H B, et al, British Medical fournal, 1977, 2, 1247.

3 Baker, S P, et al, fournal of Trauma, 1974, 14, 187.

4 Bull, J P, Accidents, Analysis and Prevention, 1975, 7, 249.

5 Bradley, J V, Distribution-free Statistical Tests, p 105. Englewood Cliffs, Cal, Prentice-Hall, 1968.

${ }^{6}$ Hoffman, E, Annals of the Royal College of Surgeons of England, 1976, 58, 233.

7 Rose, J, et al, British Medical fournal, 1977, 2, 615

(Accepted 13 September 1977)

\title{
Increased plasma adrenaline concentrations in benign essential hypertension
}

\author{
R FRANCO-MORSELLI，J L ELGHOZI， E JOLY，S DI GIUILIO，P MEYER
}

British Medical fournal, 1977, 2, 1251-1254

\section{Summary}

Plasma adrenaline, noradrenaline, and dopamine concentrations and plasma renin activity were measured in the supine position and after standing for 10 minutes in 14 patients with sustained benign essential hypertension and in five patients with labile hypertension. Results were compared with values obtained in 11 normotensive control subjects. In controls plasma noradrenaline concentrations increased with age, while plasma adrenaline values tended to decrease with age. No significant difference in mean plasma noradrenaline was found

INSERM Research Unit U7, Hôpital Necker, 75015 Paris, France R FRANCO-MORSELLI, PHD, research fellow

J L ELGHOZI, MD, resident

E JOLY, MSC, research fellow

$P$ MEYER, professor of experimental medicine and head of research unit

Service de Thérapeutique Néphrologique, Hôpital Necker, 75015 Paris, France

S DI GIUILIO, MD, resident between hypertensive and control subjects, but plasma noradrenaline seemed slightly increased in a proportion of hypertensive patients aged less than 50 .

Plasma adrenaline was considerably raised in both supine and standing positions in eight patients with sustained hypertension and in two with labile hypertension. Dopamine concentrations and plasma renin activity were similar in all groups studied. The finding of significantly raised plasma adrenaline concentrations in a large proportion of hypertensive patients supports the hypothesis that the activity of the sympathetic nervous system is increased in essential hypertension. Measurement of plasma adrenaline seems to be a more sensitive index of this activity than that of plasma noradrenaline.

\section{Introduction}

The role of the sympathetic nervous system and the adrenal medulla in the pathogenesis of hypertension was first suspected many years ago when the effects of noradrenaline and adrenaline on stimulating contraction of vascular smooth muscle and accelerating the cardiac contraction rate were discovered. Doubt was cast on this hypothesis, however, by the inconsistency of early attempts to relate hypertension to abnormal 
urinary excretion of catecholamines. ${ }^{1}$ The subsequent discovery that various potent hypotensive agents affect catecholamine metabolism led to a re-evaluation of the role of the sympathetic nervous system in hypertension. More direct evidence has been provided over the past decade or so by the development of sensitive and specific methods for measuring catecholamines in tissues. These methods were first applied to the rat, and an increase in peripheral sympathetic nerve activity has been shown in hypertension induced by deoxycorticosterone acetate and salt (DOCA-salt), ${ }^{2}$ and less consistently in the early phase of genetic hypertension. ${ }^{3}$ Raised plasma catecholamine concentrations, measured with sensitive radiometric methods, have been recently reported in many patients with essential hypertension. ${ }^{4-8}$ In most of these investigations, however, the difference between hypertensives and normotensives was slight, and the catecholamines measured in plasma were either noradrenaline alone or the sum of noradrenaline and adrenaline referred to as "total plasma catecholamines." The recent method of Da Prada and Zurcher ${ }^{9}$ permits a distinct and rapid estimation of noradrenaline, adrenaline, and dopamine in the same sample. We used this method to investigate the role of adrenaline, dopamine, and noradrenaline in essential hypertension.

\section{Patients}

Since plasma noradrenaline concentrations increase with age, ${ }^{10}$ we studied hypertensive patients and controls with a similar mean age. Fifteen men and four women with essential hypertension, 18-63 years of age, were studied. Five of them were defined as having labile hypertension - that is, average casual blood-pressure readings of less than $160 \mathrm{~mm} \mathrm{Hg}$ systolic or $95 \mathrm{~mm} \mathrm{Hg}$ diastolic, or both. The 14 other patients had benign sustained high blood pressure according to fundal, cardiac, and renal examination. All were diagnosed as essential hypertensives as no cause of high blood pressure or associated disease was detected after a complete investigation. None had received any antihypertensive medication, and all of them were on a free diet. Of the control subjects, nine were men and two were women. They were aged between 26 and 76 years, and their blood pressure never exceeded $160 / 95 \mathrm{~mm} \mathrm{Hg}$ on repeated measurements. Eight of them were students or scientists working in our laboratory. The older subjects were normotensive patients recovering from uterine haemorrhage,

TABLE I-Mean values $( \pm S E)$ for blood pressure and heart rate in patients and controls after 30 and 10 minutes in supine and standing positions respectively'

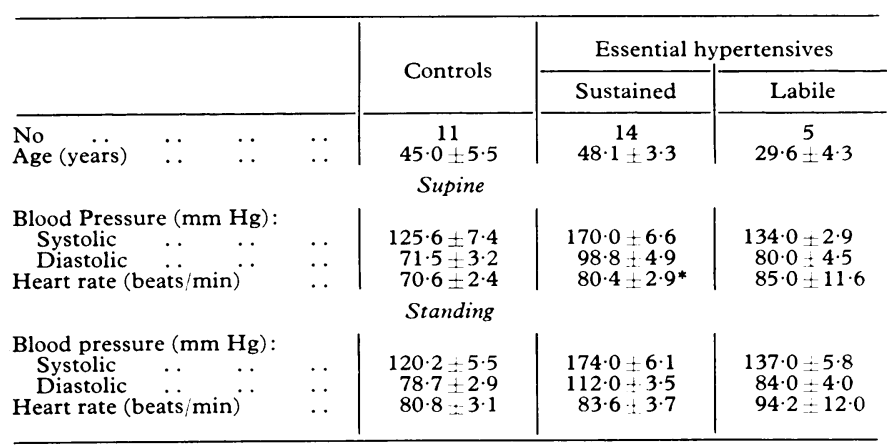

$* \mathrm{P}<0.02$ (compared with controls). respiratory infection, or malnutrition, and were considered cured by their doctor. None was receiving any drug known to interfere with the sympathetic nervous system. Controls were investigated in parallel with the hypertensive patients. The study was completed within four months.

Blood sampling was performed in the morning in a room near the laboratory. Since preliminary experiments showed no significant difference between plasma catecholamine concentrations in blood withdrawn through an indwelling catheter or by venipuncture, we chose the latter method. Patients and controls were asked to remain quietly in the supine position for 30 minutes. Their heart rate and blood pressure (measured by sphygmomanometry) were determined, and blood was withdrawn. These measurements and further blood sampling were repeated after 10 minutes with patients and controls standing still.

\section{Methods}

Blood for catecholamine estimation was placed into ice-cold tubes and centrifuged at $4 \mathrm{C}$ within 15 minutes of collection. After precipitation of proteins, ${ }^{8}$ plasma was stored at $-20^{\circ} \mathrm{C}$ until assayed (within three weeks of collection). Plasma catecholamines were measured by the radioenzymatic method of Da Prada and Zurcher, ${ }^{9}$ with minor modifications. Briefly, the noradrenaline, adrenaline, and dopamine present in 300- $\mu$ l samples are first converted to their $O$-methylated analogues by catechol- $O$-methyl transferase in the presence of ${ }^{3} \mathrm{H}-S$-adenosylmethionine. The products of this reaction ${ }^{3} \mathrm{H}$-normetanephrine, ${ }^{3} \mathrm{H}$-metanephrine, and ${ }^{3} \mathrm{H}$-methoxytyramine respectively) purified by solvent extraction and washing are separated by silica gel thin-layer chromatography. Normetanephrine and metanephrine are then converted to their vanillin equivalents by sodium metaperiodate cleavage, and counted in a liquid scintillation counter. Methoxytyramine is directly counted without undergoing the cleavage. The sensitivity of the technique was $20 \mathrm{pg} / \mathrm{ml}$ of plasma for noradrenaline and adrenaline and $17 \mathrm{pg} / \mathrm{ml}$ of plasma for dopamine. In addition to internal standards, samples from a plasma pool were run with each assay. Within-assay and interassay coefficients of variations were $11.9 \%$ for adrenaline, $8.6 \%$ for noradrenaline, and $9.7 \%$ for dopamine. Final recoveries of ${ }^{3} \mathrm{H}$-normetanephrine, ${ }^{3} \mathrm{H}$-metanephrine, and ${ }^{3} \mathrm{H}$-methoxytyramine were $31 \cdot 7 \% \pm \mathrm{SE} 0.85,30.6 \% \pm 2 \cdot 3$, and $33.5 \% \pm 1.33$ respectively. Catechol- $O$-methyl transferase was prepared by the method of Axelrod and Tomchick. ${ }^{10}$ Plasma renin activity was measured by radioimmunoassay. ${ }^{11}$ The data were analysed by the Student's $t$ test and one-way analysis of variance and of covariance using a suitably programmed Tektroniks 4051 computer.

\section{Results}

The mean values of blood pressure and heart rate (supine and standing) in controls and hypertensive patients are shown in table I. Within each group, and overall, no age-related difference in blood pressure or heart rate was found. Mean plasma catecholamine concentrations and plasma renin activity in patients and controls are shown in table II. 'Ten minutes' standing induced a significant increase in plasma noradrenaline concentrations in both patients and controls $(P<0.001)$. Plasma renin activity was also significantly increased in all subjects on standing $(P<0.001)$. Plasma adrenaline tended to increase on standing, although not significantly. Plasma dopamine did not vary.

The mean values of plasma noradrenaline and dopamine did not differ among the various groups, whereas the mean concentration of adrenaline was significantly higher in hypertensives than in controls,

TABLE II-Mean ( $\pm S E$ ) plasma catecholamine concentrations (pg/ml) and plasma renin activity (ng/ml/h) in control subjects and in patients with essential hypertension after 30 minutes (supine) and 10 minutes (standing)

\begin{tabular}{|c|c|c|c|c|c|c|c|c|}
\hline \multirow{2}{*}{ Subjects } & \multicolumn{2}{|c|}{ Adrenaline } & \multicolumn{2}{|c|}{ Noradrenaline } & \multicolumn{2}{|c|}{ Dopamine } & \multicolumn{2}{|c|}{ Plasma renin activity } \\
\hline & Supine & Standing & Supine & Standing & Supine & Standing & Supine & Standing \\
\hline $\begin{array}{l}\text { Controls }(n=11) \\
\text { Essential hypertensives }\end{array} \quad \begin{array}{l}\text { Sustained } \ddot{(n}=14) \\
\text { Labile }(n=5)\end{array}$ & $\begin{aligned} 40 \cdot 8 & \pm 5 \cdot 4 \\
84 \cdot 3 * * & =9 \cdot 4 \\
79 \cdot 3^{*} & \pm 13 \cdot 5\end{aligned}$ & $\begin{aligned} & 52 \cdot 3 \pm 8 \cdot 8 \\
& 110^{0} \cdot 8^{* *} \pm 14 \cdot 6 \\
& 110^{*} \cdot 0^{*} \pm 19 \cdot 2\end{aligned}$ & $\begin{array}{l}247 \cdot 5 \pm 56 \cdot 1 \\
290 \cdot 4 \pm 36 \cdot 1 \\
212 \cdot 0 \pm 38 \cdot 6\end{array}$ & $\begin{array}{l}559 \cdot 0 \div 126 \cdot 0 \\
514 \cdot 9 \div 41 \cdot 6 \\
424 \cdot 0 \div 39 \cdot 3\end{array}$ & $\begin{array}{l}46 \cdot 3+6 \cdot 0 \\
40 \cdot 1+4 \cdot 5 \\
38 \cdot 9+7 \cdot 6\end{array}$ & $\begin{array}{l}50 \cdot 4 \pm 8 \cdot 7 \\
44 \cdot 3 \pm 3 \cdot 7 \\
49 \cdot 0 \pm 8 \cdot 5\end{array}$ & $\begin{array}{l}1 \cdot 95 \pm 0 \cdot 30 \\
1.95 \pm 0 \cdot 24 \\
2 \cdot 05 \pm 0.49\end{array}$ & $\begin{array}{l}3 \cdot 18 \pm 0 \cdot 36 \\
2 \cdot 52 \pm 0 \cdot 28 \\
3 \cdot 08 \pm 0.66\end{array}$ \\
\hline
\end{tabular}

$* \mathrm{P}<0.05$ (compared with controls).

**P $<0.001$ (compared with controls). 
both supine and standing. No significant relation was found between systolic and diastolic blood pressures, heart rate, and the measured biochemical parameters. Plasma noradrenaline concentration increased with age in the overall population studied, in both supine and standing positions (fig 1). Although the mean plasma noradrenaline value was the same in hypertensive and normotensive patients, it seemed (in agreement with Sever et $a^{1.3}$ ) that noradrenaline concentrations tended to be higher in the group of hypertensive patients aged less than 50 years than in controls (fig 2). In contrast with noradrenaline, plasma adrenaline in the normotensive group decreased with age in both supine and standing positions (fig 3). No similar decrease with age was seen in hypertensive patients. In the hypertensive group plasma adrenaline values were often higher than those of controls, particularly. in patients aged over 35. The rise of plasma adrenaline is also illustrated in fig 4 , in which supine plasma adrenaline concentrations in controls and hypertensive patients were plotted against systolic pressure. Interestingly, when values of normotensive and hypertensive subjects were considered together, there was a positive correlation between plasma adrenaline and systolic blood pressure $(r=0.479 ; P<0.01)$. A similar positive correlation was found for diastolic blood pressure $(r=0.376 ; \mathrm{P}<0.05)$. Plasma dopamine did not change with age and blood pressure. We found plasma renin

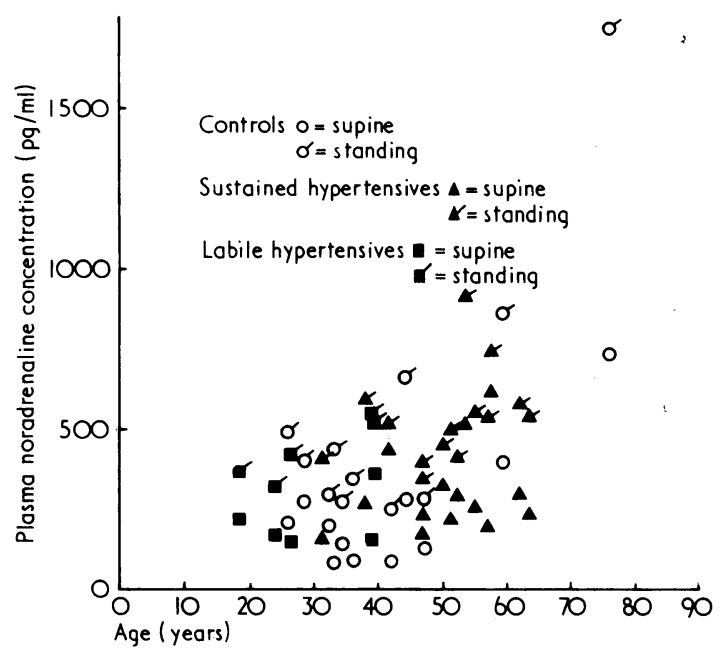

FIG 1 - Relation between plasma noradrenaline concentra tion and age in hypertensive patients and normotensive controls. A correlation was found for controls in both supine $(\mathrm{r}=0.809 ; \mathrm{P}<0.01)$ and standing positions $(\mathrm{r}=0.75$; $\mathrm{P}<0.01)$, but not for hypertensives.

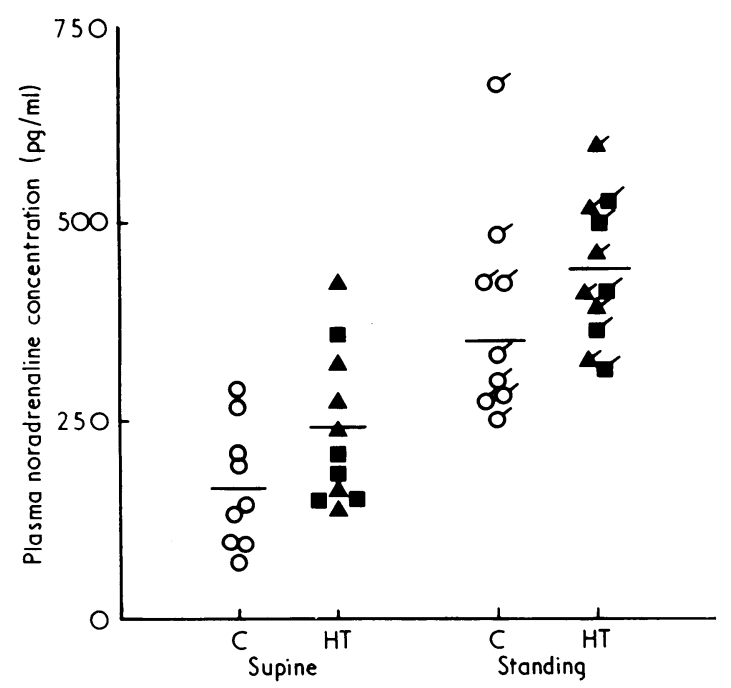

FIG 2-Plasma noradrenaline concentration in controls (C) and hypertensive (HT) patients aged less than 50 years. Symbols as in key to fig 1 .

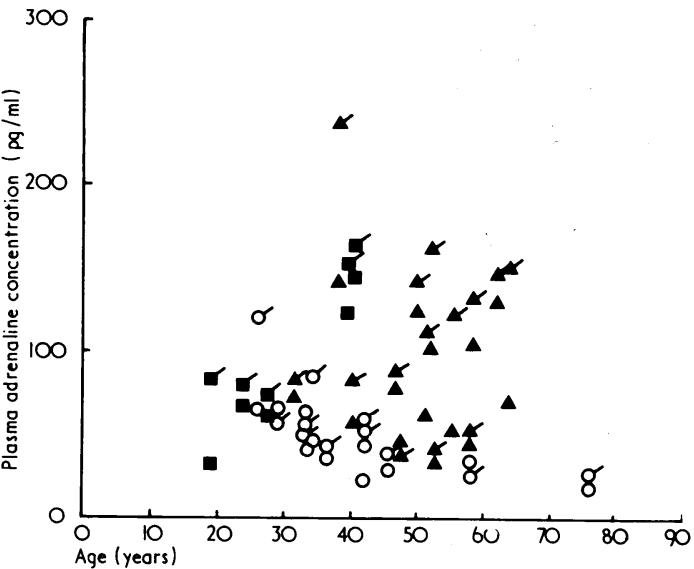

FIG 3-Relation between plasma adrenaline concentration and age. A negative relationship was found for controls in supine $(r=0.854 ; \quad P<0.001)$ and standing positions $(\mathbf{r}=0.732 ; \mathrm{P}<0.01)$. No significant correlation was foun for the other two groups. Symbols as in key to fig 1 .



FIG 4-Relation between plasma adrenaline concentration and systolic blood pressure in supine position. No significant relation was found for the three groups considered separately; when values were considered together a positive correlation was observed $(r=0.479 ; P<0.01)$.

$\mathrm{O}=$ controls $; \quad \boldsymbol{A}=$ sustained hypertensives; $\quad \boldsymbol{Q}=$ labile hypertensives.

activity to be identical in normotensive and hypertensive subjects; it was not influenced by age and did not seem to be correlated with plasma catecholamines.

\section{Discussion}

We found that supine and standing plasma noradrenaline concentrations increased with age, which agrees with previous reports. ${ }^{1213}$ In disagreement with some investigators, ${ }^{4-8}$ but not others, ${ }^{12}{ }^{1314}$ we did not find a statistically significant difference between mean plasma noradrenaline concentrations in normotensive and hypertensive subjects either at rest or on standing, although Sever et al ${ }^{13}$ found a significant difference between controls and hypertensive patients aged less than 50 . We also found that plasma noradrenaline concentrations in hypertensives aged less than 50 years tended to be higher. Interestingly, the percentage of hypertensives having plasma noradrenaline values above the range of controls values was approximately the same in our study as in that of Sever et al. ${ }^{13}$ 
Measurement of adrenaline concentrations gave more significant results. In normotensive subjects, plasma adrenaline tended to decrease with age, and the increment when standing was moderate. Plasma adrenaline concentrations were considerably raised in a significant number of patients with hypertension, either labile or sustained. The higher plasma adrenaline concentrations were mainly observed in hypertensive subjects over the age of 35 . An increase in mean heart rate was observed in hypertensives, but no significant correlation was found between this and plasma adrenaline.

Few investigators have tried to measure circulating adrenaline. Engelman et $a l^{4}$ found that total plasma catecholamines were increased in hypertension without simultaneous variations in the noradrenaline:adrenaline ratio, which suggested an increase in plasma concentrations of adrenaline. Conversely, Pedersen and Christensen ${ }^{14}$ and Esler et al ${ }^{15}$ reported no significant variation in plasma adrenaline concentrations between normotensive and hypertensive subjects. It is not easy to explain these contradictory results. It should be realised, however, that they were obtained with methods less sensitive than the radiometric assay used by us. Moreover, Esler et $a l^{15}$ studied young patients (aged less than 35 years), and our results seem to show that the rise in plasma adrenaline concentrations is more pronounced in older subjects.

The discrepancy between the results of measurements of plasma noradrenaline and adrenaline in hypertensives that we have observed may be interpreted in two ways. The first proposes that adrenaline released directly into the blood stream from the adrenal medulla is a direct index of splanchnic nerve activity. The second suggests that the amount of noradrenaline entering the blood, although reflecting the activity of peripheral sympathetic nerves, ${ }^{16}$ depends on many factors which may hamper the sensitivity of plasma noradrenaline measurements. These factors include neuronal release, reuptake into nerve terminals, extraneuronal tissue uptake, metabolism, and diffusion from the nerve endings to the lumen of the vessels.

Nevertheless, the more obvious increase in plasma adrenaline as compared with plasma noradrenaline may simply reflect an increase in sympathoadrenomedullary activity over general sympathetic activity. This is supported by various data from studies on animals. In DOCA-salt hypertension the conversion of radioactive tyrosine into catecholamines was found to be increased in the adrenal glands, ${ }^{17}$ and the amelioration of hypertension resulting from bilateral adrenalectomy showed that increased catecholamine synthesis might contribute to the maintenance of high blood pressure. Such a lowering effect was not observed in normotensive animals. ${ }^{18}$ Similarly, increased catecholamine content and rates of synthesis and secretion of catecholamines were found in adrenal glands of spontaneously hypertensive rats of the Japanese $\operatorname{strain}^{1920}$; in these animals adrenalectomy seemed either to prevent the development of hypertension or to lower it, once established. ${ }^{21} 22$

The finding of an increased activity of the adrenal glands in human hypertension is consistent with the reduction of high blood pressure which has been indisputably observed in a significant, though not strictly defined, proportion of patients undergoing sympathectomy, splanchnicotomy, and partial adrenalectomy before oral preparations of antihypertensive drugs were available. ${ }^{23}$ Unlike adrenaline and noradrenaline, dopamine concentrations showed no change with posture, which supports the observation ${ }^{24}$ that plasma dopamine increases only with exhaustive exercise. Age did not influence plasma dopamine concentrations: these were similar in hypertensive and control subjects. No variation in plasma dopamine has been reported in other cases of altered adrenergic activity such as long fasting, or in neuroplegic patients. ${ }^{25}$ Thus circulating concentrations of this amine seem to be independent of sympathetic activity, and the physiological significance of dopamine in plasma has to be further investigated.

Renin release from the kidney may be regulated by the sympathetic nervous system in certain conditions. ${ }^{26}$ De Quattro and Miura $^{2}$; found a positive relation between plasma catecholamines and plasma renin activity. In agreement with Louis et al: we found no such relation, indicating that renin secretion in hypertension is not entirely controlled by the sympathetic nervous system. Although our observations provide additional evidence implicating the sympathetic nervous system in hypertension, they do not indicate whether the increased nervous activity is a primary or secondary cause of the rise in blood pressure. They may, however, be useful in directing the choice of antihypertensive drugs. Patients with raised plasma concentrations of catecholamines may respond better to drugs acting through the nervous system. The clinical importance of labile hypertension is still debated. Some investigators ${ }^{2 *}$ think that it may lead to permanent hypertension. We found considerably raised concentrations of plasma adrenaline in two out of five patients with labile hypertension. It would be interesting to know whether the development of sustained hypertension is restricted to patients with increased plasma adrenaline concentrations.

This work was supported by grants from INSERM, CNRS, DGRST, and Lers-Synthelabo (Paris). We thank Professor G Bartholini, Dr P Scatton, and Dr P L Morselli (Lers-Synthelabo) for their advice, and Mrs Pasques (INSERM U25) for her skilful technical assistance.

Requests for reprints should be addressed to Mrs R FrancoMorselli, INSERM U7, Hôpital Necker, 161 Rue de Sèvres, 75015 Paris, France.

\section{References}

${ }^{1}$ De Champlain, J, in Perspectives in Neuropharmacology, ed S Sneider, p 215. London, Oxford University Press, 1972.

2 De Champlain, J, Krakoff, L R, and Axelrod, J, Circulation Research, 1967, 20, 136.

${ }^{3}$ Grobecker, H, et al, Clinical Science and Molecular Medicine, 1976, 51, 377.

4 Engelman, K, Portnoy, B, and Sjoerdsma, A, Circulation Research, 1970, 26 (suppl 1), 141.

${ }^{5}$ De Quattro, V, and Chan, S, Lancet, 1972, 1, 806.

${ }^{6}$ Geffen, L B, et al, Clinical Science and Molecular Medicine, 1973, 44, 617.

${ }^{7}$ Louis, W J, et al, Circulation Research, 1974, 34 (suppl 1), 57.

${ }^{8}$ De Champlain, J, et al, Circulation Research, 1976, 38, 109.

${ }^{9}$ Da Prada, M, and Zurcher, G, Life Sciences, 1976, 19, 1161.

${ }_{10}$ Axelrod, J, and Tomchick, R, fournal of Biological Chemistry, 1958, 233, 702 .

${ }^{11}$ Grünfeld, J P, et al, Clinical Science and Molecular Medicine, 1975, 48, 391.

${ }_{12}$ Lake, C R, et al, New England fournal of Medicine, 1977, 296, 208.

${ }^{13}$ Sever, P S, et al, Lancet, 1977, 1, 1078.

${ }_{14}$ Pedersen, E B, and Christensen, N J, Acta Medica Scandinavica, 1975, 198, 373.

${ }^{15}$ Esler, M, et al, New England fournal of Medicine, 1977, 296, 406.

${ }^{16}$ Lancet, 1977, 1, 1088.

17 De Champlain, J, Muller, R A, and Axelrod, J, Circulation Research, 1969, $25,285$.

${ }^{18}$ De Champlain, J, and Van Ameringen, M R, Circulation Research, 1972, 31, 617.

19 Ozaki, M, et al, fapanese Circulation fournal, 1968, 32, 1367.

${ }^{20}$ Morisawa, T, fapanese Circulation fournal, 1968, 32, 177.

${ }^{21}$ Aoki, K, fapanese Heart fournal, 1963, 4, 443.

22 Ozaki, M, fapanese fournal of Pharmacology, 1966, 16, 257.

2:3 Smithwick, R H, and Thompson, J E, fournal of the American Medical Association, 1953, 152, 1501.

${ }^{24}$ Callingham, B A, and Barrand, N Y, fournal of Pharmacy and Pharmacology, 1976, 28, 356

${ }^{25}$ Christensen, N J, Mathias, C J, and Frankel, H L, European fournal of Clinical Investigation, 1976, 6, 403

${ }^{26}$ Zanchetti, A, et al, American fournal of Cardiology, 1976, 37, 675.

27 De Quattro, V, and Miura, Y, American fournal of Medicine, 1973, 55, 362.

${ }^{28}$ Frohlich, E D, et al, Circulation Research, 1970, 26 (suppl 1), 55.

(Accepted 13 September 1977) 